\title{
Acute Stroke Management: Endovascular Options for Treatment
}

\author{
Mikayel Grigoryan, M.D., ${ }^{1}$ and Adnan I. Qureshi, M.D. ${ }^{1}$
}

\section{ABSTRACT}

The management of acute ischemic stroke has advanced greatly over the past 2 decades. New interventions, including intravenous and endovascular treatment strategies, have evolved to recanalize arteries and salvage the ischemic brain. The evolution of interventional approaches to the treatment of acute stroke has been prompted by the limitations of intravenous therapy and intended to extend the treatment window, improve recanalization rates, and subsequently long-term clinical outcomes. The major techniques that have defined the current field of interventional acute stroke management and the relevant past and current data, and ongoing clinical trials on interventional stroke therapy will be reviewed. New issues, such as futile recanalization, and time to microcatheter, will also be discussed.

KEYWORDS: Acute stroke, intraarterial thrombolysis, mechanical thrombectomy, recombinant tissue plasminogen activator, angioplasty, stenting

Stroke remains a major health care challenge worldwide and is the third leading cause of death and the leading cause of disability in Western countries. ${ }^{1}$ It is estimated that almost 800,000 strokes occur yearly in the United States, $80 \%$ of which are ischemic in nature. ${ }^{1}$ Reperfusion of the ischemic brain is the cornerstone of effective therapy for acute ischemic stroke. By restoring blood flow to the tissue at risk before it progresses to infarction, reperfusion therapies salvage ischemic penumbra, reduce final infarct volume, and ultimately result in better clinical outcomes. Prompt initiation of these therapies has been established as a standard of care and includes both well-established medical therapies and exciting new endovascular strategies.

Removal of a clot under direct angiographic visualization has obvious advantages over systemic intravenous administration of a thrombolytic. The era of endovascular therapy for acute ischemic stroke began over 20 years ago with the first reported use of intraarterial (IA) administration of thrombolytic agents. ${ }^{2-6}$ Since the approval in 1996 by the United States Food and Drug Administration (FDA) of intravenous (IV) thrombolysis with recombinant tissue plasminogen activator (rtPA, alteplase) for the treatment of acute ischemic stroke, ${ }^{7}$ the evolution of interventional treatment has been stimulated by the limitations of IV therapy, to help those acute stroke patients who are either ineligible or fail to respond to IV rtPA therapy.

Devices and techniques for the interventional treatment of acute ischemic stroke have been evolving rapidly (Table 1), making the execution of large randomized clinical trials of interventional therapies in acute stroke difficult as the technology development cycle far outpaces the enrollment periods. Large trials sponsored by the National Institute of Neurological Disorders and Stroke (NINDS), both the Interventional Management

\footnotetext{
${ }^{1}$ Zeenat Qureshi Stroke Research Center, University of Minnesota, Minneapolis, Minnesota.

Address for correspondence and reprint requests: Mikayel Grigoryan, M.D., Endovascular Surgical Neuroradiology Fellow, Department of Neurology, University of Minnesota, Minneapolis, MN 55455 (e-mail: mikayel@gmail.com).
}

Stroke; Guest Editor, Kelly D. Flemming, M.D.

Semin Neurol 2010;30:469-476. Copyright (C) 2010 by Thieme Medical Publishers, Inc., 333 Seventh Avenue, New York, NY 10001, USA. Tel: +1(212) 584-4662.

DOI: http://dx.doi.org/10.1055/s-0030-1268868.

ISSN 0271-8235. 
Table 1 Common Interventional Strategies in Acute Ischemic Stroke

\begin{tabular}{ll}
\hline Interventional Strategies & Agents/Devices \\
\hline Intraarterial thrombolysis & Plasminogen activators, direct fibrinolytics, fibrinogenolytic agents \\
Endovascular thrombectomy & Distal and proximal devices: Merci*, Neuronet, Alligator, etc. \\
Endovascular thromboaspiration & Penumbra*, AngioJet, etc. \\
Thrombus disruption/entrapment & Balloon angioplasty, stents, microguidewire, snares
\end{tabular}

*Merci and Penumbra devices have been approved by the FDA to "remove blood clots from the brain in patients experiencing an ischemic stroke." Other agents and devices constitute off-label and/or investigational use.

of Stroke-III (IMS-III) and MR and Recanalization of Stroke Clots Using Embolectomy (MR RESCUE), have been revised to include newer device technology that have FDA approval. ${ }^{8}$ The community awaits the data from these large RCTs, but in the interim we rely on a lower level of evidence to guide the interventional treatment of acute ischemic stroke.

\section{INTRAARTERIAL THROMBOLYSIS}

One of the main limitations to IV rtPA since its approval has been the strict 3-hour time window for initiating therapy (benefit in the 3- to 4.5-hour window was subsequently established by the Third European Cooperative Acute Stroke Study (ECASS-III ) in a more restricted subgroup of patients $\left.{ }^{9}\right)$. This window, combined with a lack of public awareness of stroke, has unfortunately limited the use of IV thrombolysis to $<5 \%$ of eligible candidates. ${ }^{10,11}$ Intraarterial thrombolysis (IAT) was first studied as an alternative to IVT in an attempt to expand this time limit. The idea behind IAT is rapid local delivery of thrombolytic agent through a microcatheter placed near the site of occlusion. It is usually infused over 1 to 2 hours while serial angiographic studies are obtained. Theoretically, this should lead to improved recanalization, a proven biomarker of therapeutic activity of thrombolytic treatment in acute ischemic stroke, ${ }^{12}$ as well as reduced hemorrhagic complications (due to the use of lower doses of pharmacologic thrombolytics). As with other interventional techniques used in acute stroke, the major disadvantages to IAT include the relative complexity of the procedure, the level of required technical expertise, relatively selective availability, delays in initiating treatment, and the additional risks and expense of an invasive procedure compared with IVT. ${ }^{13}$

The thrombolytics that have been reported for IAT use in acute stroke include urokinase, prourokinase, streptokinase, alteplase, and reteplase. ${ }^{13,14}$ In general, the nonfibrin-selective drugs (e.g., urokinase and streptokinase) can result in systemic hypofibrinogenemia, whereas the fibrin-selective agents (e.g., alteplase and r-prourokinase) are theoretically mostly active at the site of thrombosis. No direct-comparison trials have been reported between any of these agents and the choice, composition, and dose of agent is usually institution- specific. Recanalization rates for IAT have been shown to be superior to those for IVT for major cerebrovascular occlusions, averaging $70 \%$ versus $34 \% .{ }^{15}$ The differences in recanalization were most apparent with large vessel occlusions, such as proximal middle cerebral artery (MCA), and extra- and intracranial internal carotid artery (ICA; carotid artery "T" occlusion, Fig. 1$).{ }^{16}$

The efficacy and safety of intraarterial thrombolytic infusion using $r$-prourokinase ( $r$-pro)-based therapy was established in the PROACT I and II (Prolyse in Acute Cerebral Thromboembolism) studies, ${ }^{17,18}$ which were randomized, multicenter, controlled trials. In these studies, subjects with a MCA occlusion (baseline $\mathrm{Na}$ tional Institutes of Health Stroke Scale [NIHSS] score of 17) were randomized to IA prourokinase plus IV heparin or intraarterial placebo with IV heparin initiated within 6 hours of onset. The primary clinical outcome (modified Rankin Scale [mRS] score $\leq 2$ ), was achieved in $40 \%$ of the patients in the rpro-UK treatment group, compared with $25 \%$ in the control group (absolute benefit $15 \%$, relative benefit $58 \%$; number needed to treat $=7 ; p=0.043)$. Although encouraging, the results of PROACT-II were considered insufficient to grant FDA approval for IA rpro-UK use in acute stroke, and another larger trial was requested, which to date has not been undertaken.

\section{COMBINED INTRAVENOUS AND INTRAARTERIAL THROMBOLYSIS}

Several studies have evaluated the feasibility, safety, and efficacy of combined IV rtPA with IAT in patients with acute stroke. ${ }^{19-22}$ This approach has the potential of combining the advantages of IV rtPA (fast and easy to use) with the advantages of IAT (directed therapy, titrated dosing, and higher rates of recanalization), thus improving the speed and frequency of recanalization. The first of such trials was the Emergency Management of Stroke (EMS) Bridging trial in $1999,{ }^{20}$ in which 35 patients with acute stroke were randomized to first receive partial dose of IV-rtPA $(0.6 \mathrm{mg} / \mathrm{kg})$ or placebo followed by IA-rtPA if the vessel remained occluded. Even though $70 \%$ of patients who received IV-rtPA still had angiographically confirmed residual thrombus requiring IAT, those who received the combination of IV-/IA-rtPA had significantly more TIMI 
A
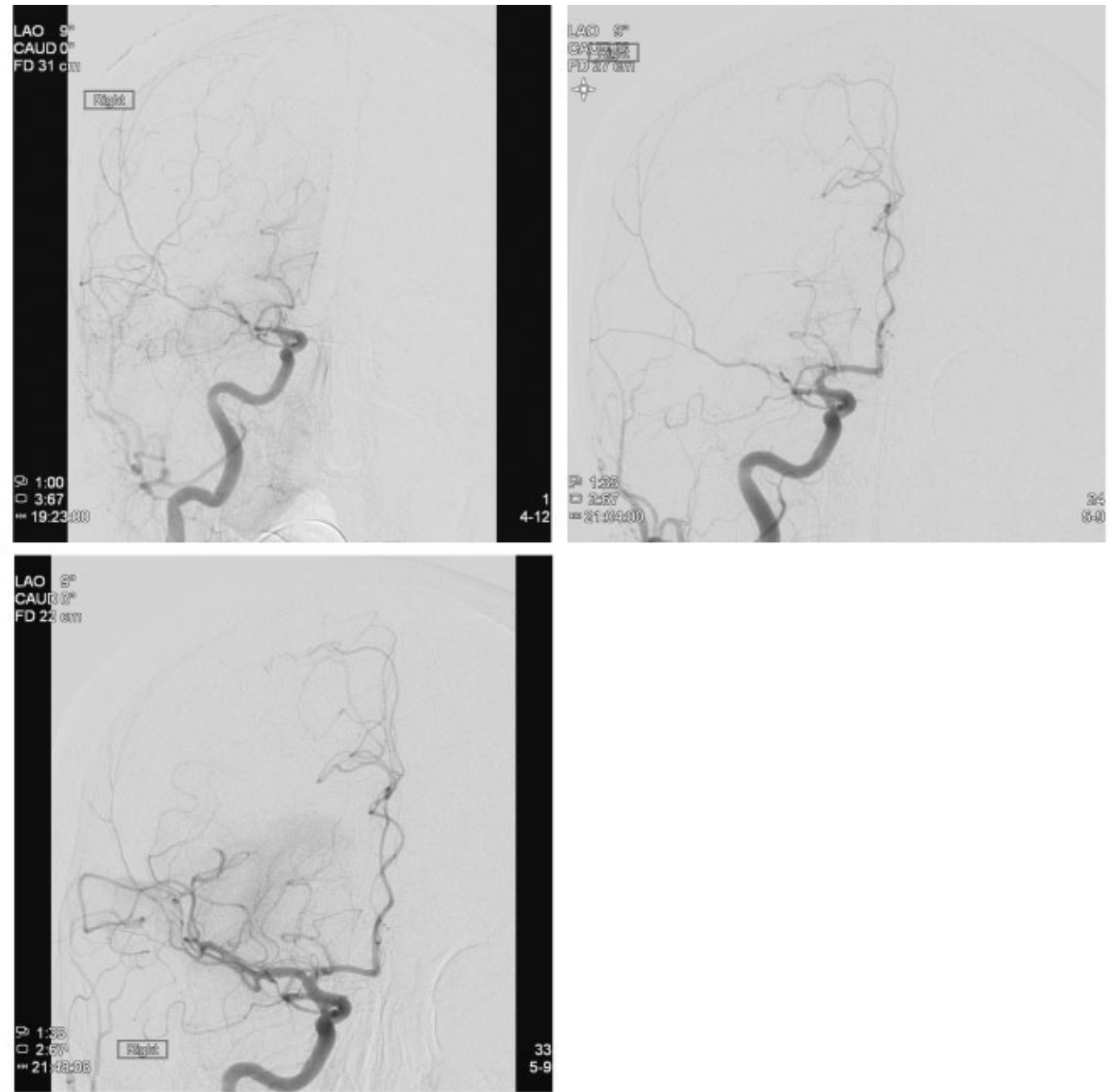

Figure 1 A 54-year-old woman presented with sudden left-sided weakness, and an National Institutes of Health Stroke Scale (NIHSS) of 20. Intravenous recombinant tissue-type plasminogen activator at 1.5 hours after the symptom onset did not result in any improvement. (A) She was emergently taken to an endovascular suite, where an angiogram demonstrated a right carotid terminus occlusion. (B) Administration of intraarterial thrombolytics via microcatheter resulted in recanalization of the right anterior cerebral artery, (C) followed by the right middle cerebral artery. She was discharged 5 days later with an NIHSS of 5 .

(Thrombolysis in Myocardial Infarction) 3 MCA recanalizations than the placebo group (55\% vs. $10 \%)$, while hemorrhagic complication rates were similar. However, the clinical outcomes were found to be no different between the two groups. Several other studies assessed the feasibility of a bridging approach by using full-dose IV-rtPA, overall supporting the safety of IAT after its administration. ${ }^{23-25} \mathrm{~A}$ recently published meta-analysis comparing partial vs. full-dose IV-rtPA followed by endovascular treatment suggested that a full-dose IVT is safe and may result in higher recanalization rates and better functional outcome at 3 months. ${ }^{26}$

A "reversed bridging" approach has also been proposed. In a study by Keris et $\mathrm{al}^{27} 12$ patients with proximal vessel occlusions received IAT first with IV$\mathrm{rtPA}$ administered afterwards in the intensive care unit.
The control group included 33 patients who did not undergo any thrombolysis. There were no symptomatic intracerebral hemorrhages, and at 12 months, $83 \%$ of the patients in the thrombolysis group were functionally independent, whereas only $33 \%$ of the control subjects had a good outcome. The mortality rates at 12 months were $17 \%$ and $64 \%$, respectively.

The largest prospective trial to date to study combined therapy was the IMS (Interventional Management of Stroke) trial published in $2004 .{ }^{28}$ Eighty patients with a medial baseline NIHSS score of 18 received IV-rtPA within 3 hours of onset followed by a 2-hour infusion of IA-rtPA (maximum dose of $22 \mathrm{mg}$ ). Primary comparisons were with a similar subset of placebo- and IV-rtPA-treated patients from the NINDS rtPA trial. The 3-month mortality rate of $16 \%$ was less, but not 
statistically different from that observed in the placebo (24\%) and rtPA treatment (21\%) groups from the NINDS trial. The rate of symptomatic intracerebral hemorrhage $(6.3 \%)$ was similar to the rtPA-treated group (6.6\%), but higher than that in the placebo group (1\%). The patients in the IMS trial had significantly better outcomes at 3 months (56\%) than the NINDS placebo group for all outcome measures.

In the IMS II trial, ${ }^{29,30}$ subjects ages 18 to 80 years with a baseline NIHSS score $>10$ had IV-rtPA $(0.6 \mathrm{mg} /$ $\mathrm{kg}$ over 30 minutes) started within 3 hours of onset. For subjects with an arterial occlusion demonstrated at angiography, additional rtPA was administered via the EKOS microinfusion catheter (EKOS Corp., Bothell, WA) or a standard microcatheter at the site of the thrombus up to a total dose of $22 \mathrm{mg}$ over 2 hours of infusion or until thrombolysis had been achieved. Overall, all IMS II subjects treated with IA-rtPA via either microcatheter had a 60\% (33/55) TICI/TIMI 2 and 3 reperfusion grade flow after completion of the IAT. The 3 -month mortality in IMS II subjects was $16 \%$, and $46 \%$ of subjects had an mRS of 0 to 2 .

The ongoing IMS III trial ${ }^{31}$ is a phase III randomized multicenter open-label clinical trial determining the efficacy of the combined IVT/IAT approach to treat acute stroke. The patients are randomized to receive IV-rtPA-alone or IVT/IAT combination. The patients in the IVT/IAT arm will receive IV-rtPA and undergo immediate angiography. If an appropriate thrombus is identified, the neurointerventionalist may select either a standard or EKOS microcatheter to infuse rtPA, or select one of mechanical devices: the Merci retriever or Penumbra system, per user preference. The primary outcome measure is the rate of good clinical outcomes $(\mathrm{mRS} \leq 2)$ at 90 days. The primary safety measure is mortality at 3 months and symptomatic intracerebral hemorrhage within the 24 hours of randomization. The trial began enrollment in 2006, with 320 of 900 subjects currently enrolled.

\section{ENDOVASCULAR THROMBECTOMY (THE MERCI RETRIEVER)}

The risk of symptomatic intracerebral hemorrhage and limited time constraints associated with thrombolytic agents prompted a search for alternate means of recanalization in acute ischemic stroke. The Merci retriever was the first stroke device to be approved by the FDA, and thus launched the era of mechanical thrombectomy. ${ }^{32,33}$ The device was initially approved in August 2004 and is currently labeled under the following indication: "To restore blood flow in the neurovasculature by removing thrombus in patients experiencing ischemic stroke. Patients who are ineligible for treatment with IV-rtPA or who fail IV-rtPA therapy are candidates for treatment." It consists of a flexible tapered nitinol wire with 5 helical loops that can be threaded in the thrombus for retrieval.

The Mechanical Embolus Removal in Cerebral Ischemia (MERCI) trial was a prospective single-arm multicenter trial designed to test the safety and efficacy of the Merci clot retrieval device to restore the patency of intracranial arteries within the first 8 hours of an acute stroke in 141 patients. ${ }^{33}$ In the overall group, $48 \%$ of occluded vessels were recanalized with a $7.1 \%$ rate of clinically significant procedural complications, a $7.8 \%$ rate of symptomatic intracerebral hemorrhage, and a $44 \%$ 3-month mortality rate. The recanalization was significantly higher than the $18 \%$ rate of recanalization with microcatheter placement in the PROACT II study. Device complications included vascular perforation, intramural arterial dissection, or embolization of a previously unaffected vascular territory. In addition, patients in whom recanalization was successful were more likely to experience a good neurologic outcome $(\mathrm{mRS} \leq 2)$ at 90 days ( $46 \%$ vs. $10 \%$, respectively) and mortality rate was lower ( $32 \%$ vs. $54 \%$, respectively). In a multivariate logistic regression analysis, successful revascularization, younger age, and baseline NIHSS score were the strongest predictors of good outcome at 90 days. Alternatively, the absence of recanalization, older age, and higher NIHSS scores were independently associated with 90-day mortality.

The subsequent Multi-MERCI trial ${ }^{34}$ was an international multicenter single-arm trial with the following three objectives: to gain greater experience with the first-generation Merci retrievers in patients ineligible for IV-rtPA, to explore the safety and technical efficacy of the retriever in patients treated with IV-rtPA who failed to recanalize, and to collect safety and technical efficacy data on a second-generation Merci retriever. Of 164 patients treated with a Merci retriever, $68 \%$ of the occluded vessels were recanalized with a $5.5 \%$ rate of clinically significant procedural complications, a $9.8 \%$ rate of symptomatic intracerebral hemorrhage, and a $34 \%$ mortality rate at 90 days. Additionally, despite the inclusion of patients receiving IV-rtPA, there was no statistical difference in the symptomatic intracerebral hemorrhage rate or procedure-related complications compared with earlier MERCI trials, indicating that preprocedural IV-rtPA is safe. Much like earlier MERCI trials, Multi-MERCI demonstrated that patients in whom successful recanalization is achieved, were more likely to have a good neurologic outcome $(\mathrm{mRS} \leq 2)$ at 90 days ( $49 \%$ vs. $10 \%$, respectively) and the mortality was lower ( $25 \%$ vs. $52 \%$, respectively).

The 90-day mortality in MERCI and MultiMERCI was higher than the control arm of the PROACT II. However, because the MERCI trials were not limited to MCA occlusions and in the end enrolled older patients with a more severe baseline stroke score than PROACT II, comparisons between these trials cannot 
be made. Last year, the Merci and Multi-Merci investigators reanalyzed their data for patients who would have been eligible for enrollment in PROACT II. ${ }^{35}$ They were able to conclude that mortality was indeed explained by baseline stroke characteristics and trial design, and did not differ between the relevant patients in the MERCI trials and PROACT II control arm. Mechanical embolectomy produced similar functional outcome results in this subset of MERCI/MultiMERCI patients as compared with the PROACT II treatment arm.

\section{ENDOVASCULAR THROMBOASPIRATION (THE PENUMBRA SYSTEM)}

The Penumbra system is the second (and so far, the last) FDA-approved device specifically developed for the purpose of clot removal in acute ischemic stroke. This system provides a dual approach to clot extraction using aspiration and debulking of the thrombus to reduce or eliminate the clot burden. This is followed by clot retrieval with a ring device if needed that engages the thrombus by capturing it in clasps with a cylinder that is then withdrawn during flow arrest. ${ }^{36}$ The results of The Penumbra Pivotal Stroke Trial ${ }^{37}$ published in 2009 showed that this new aspiration device has a high rate of "target vessel" recanalization (>80\%) and excellent safety profile $(<3 \%$ procedural serious adverse events). The rate of symptomatic intracranial hemorrhage (11.2\%) trended higher than the MERCI trials, but was deemed acceptable in light of the aforementioned benefits.

On the other hand, the clinical outcome (mRS $\leq 2$ at 90 days) was unexpectedly low at $25 \%$ (29\% in patients with successful recanalization), bringing into question the role of recanalization in positive functional recovery. One frequently mentioned problem of this device is clot fragmentation with distal embolization. ${ }^{38}$ This is often managed with the use of smaller Penumbra devices to aspirate the fragments or adjunctive IAT. Reviewing posttrial data published experience with the Penumbra system, it appears that the device is demonstrating higher functional recovery rates around $45 \%$ in recanalized patients. ${ }^{39}$

\section{ANGIOPLASTY AND/OR STENT PLACEMENT}

Many studies have shown the feasibility and high efficacy of percutaneous transluminal angioplasty (PTA) in acute stroke. ${ }^{40-42}$ The largest study of angioplasty for acute stroke was conducted by Nakano et al. ${ }^{41}$ Thirty-six patients presenting with acute strokes underwent thrombolytic therapy alone, and 34 other patients were treated first with PTA and subsequent thrombolytic therapy was added if needed for distal embolization. Partial or complete recanalization was achieved in $63.9 \%$ versus $91.2 \%$, symptomatic intracerebral hemorrhage was seen in $19.4 \%$ versus $2.9 \%$, and good outcome ( $\mathrm{mRS} \leq 2)$ occurred in $50 \%$ versus $73.5 \%$ of the patients, respectively. PTA may be particularly useful in cases of atherothrombotic disease, in which the residual stenosis may reduce flow sufficiently to lead to rethrombosis. ${ }^{43}$ Given the risks of procedural complications, such as vessel rupture and distal embolization, this technique is generally reserved as salvage therapy for patients whose flow cannot be restored by more conservative methods. Low-pressure, more compliant balloons are being used to improve its safety. ${ }^{44}$

One of the most exciting recent developments in the interventional treatment of acute ischemic stroke was perhaps the use of self-expanding stents for flow restoration. The first prospective FDA-approved trial, StentAssisted Recanalization in Acute Ischemic Stroke, demonstrated $100 \%$ recanalization rate in 20 patients. ${ }^{45}$ There was only 1 (5\%) symptomatic hemorrhage and 1 month mRS was 0 or 1 in $45 \%$ of the treated patients. The disadvantage of this approach is the implantation of a permanent vascular prosthesis and the necessity of dual-antiplatelet therapy. Unique solutions, such as temporary stent-bypass with a retrievable device, may be able to provide an optimal interventional treatment. ${ }^{46}$

\section{SPECIAL CONSIDERATIONS}

\section{Angiographic Assessment of Severity of Occlusion and Recanalization}

Angiographic occlusion and recanalization is classified by using either the TIMI grading scale ${ }^{47}$ or the Qureshi grading scale (Fig. 2). ${ }^{48}$ The TIMI is a 4-point scale from 0 (complete occlusion) to 3 (complete recanalization), which was originally developed to assess arterial occlusion and perfusion in patients with myocardial infarction, and was later adopted for use in stroke by the PROACT II trial. The TIMI grading system does not account for occlusion location or collateral circulation. The Qureshi grading system (Fig. 2) is a scale from 0 (best possible score) to 5 (worst possible score), which angiographically classifies arterial occlusion and recanalization. It was specifically designed for ischemic stroke to address the limitations of the preexisting TIMI grading system and has been validated for use in acute stroke. ${ }^{48,49}$

\section{Futile Recanalization}

Despite the fact that recanalization is the goal of thrombolysis, it is well recognized that it fails to improve outcomes in a subset of patients with acute ischemic stroke. In the IMS II trial, $45 \%$ of subjects who achieved partial or complete reperfusion had a poor 3-month outcome $(\mathrm{mRS} \geq 3)$. In the PROACT II trial, the 


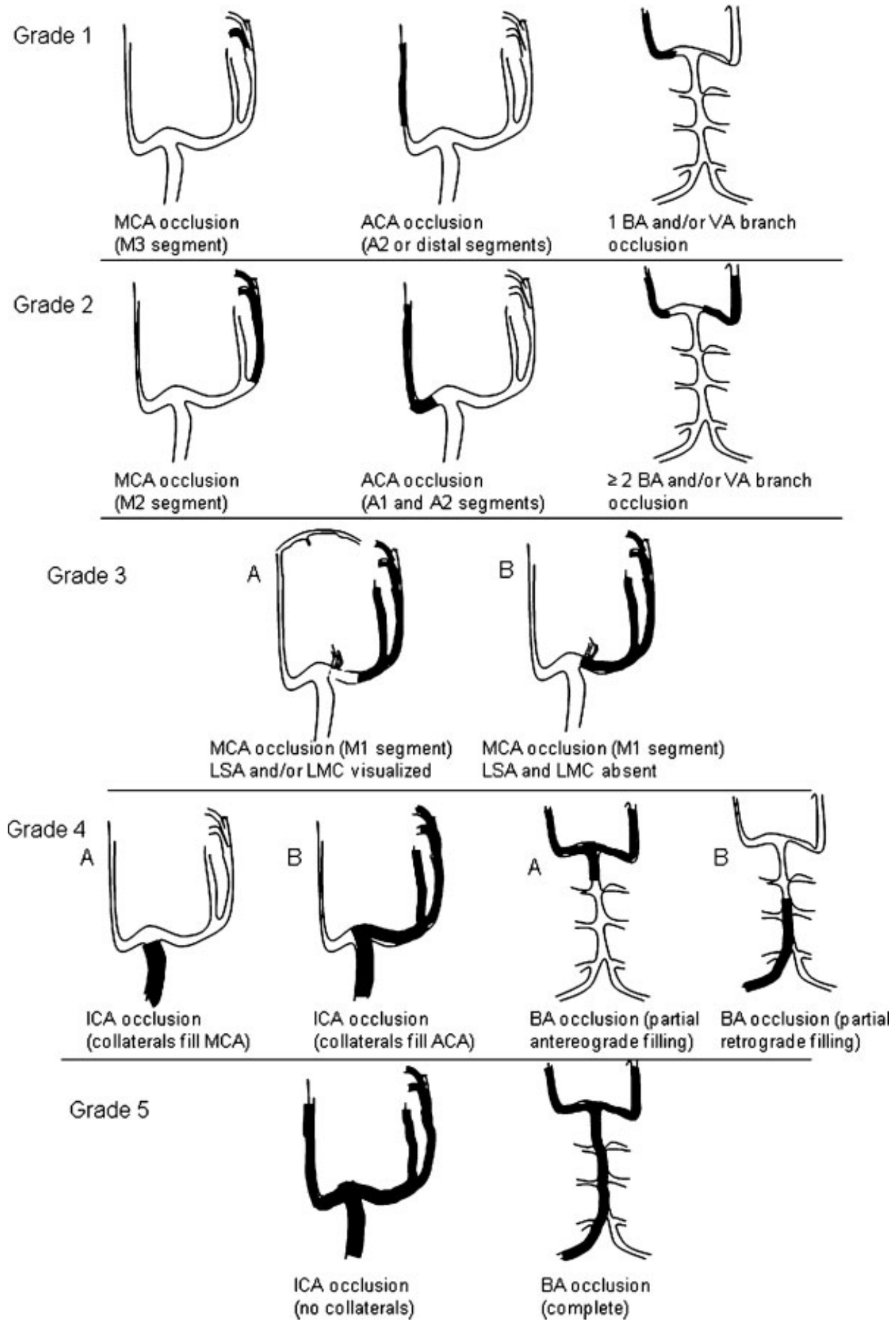

Figure 2 The Qureshi Grading Scale. ACA, anterior cerebral artery; BA, basilar artery; LSA, lenticulostriate arteries; LMC, leptomeningeal collaterals; MCA, middle cerebral artery; VA, vertebral artery.

mismatch between recanalization and favorable outcome was $26 \%$. Similarly, the MERCI and the Multi-MERCI trials had a $34 \%$ and $36 \%$ rate of futile recanalizations. In a recent multicenter study, ${ }^{50}$ Hussein et al observed futile recanalization in $49 \%$ of patients who received endovascular treatment for acute ischemic stroke. In this study, age $>70$ years (OR 4.4, 95\% CI 1.9-10.5), initial
NIHSS score $>10-19$ (OR 3.8, 95\% CI 1.7-8.4; $p<0.001$ ), and initial NIHSS score $\geq 20$ (OR 64.4, 95\% CI 28.8-144, $p<.0001)$ emerged as independent predictors of futile recanalization. Given the amount of time and resources invested and the logistics required for interventional treatment in acute stroke, more careful patient selection to avoid futile recanalization is needed. 


\section{Time to Microcatheter}

At present, no time recommendation for initiation of endovascular treatment in acute ischemic stroke is available. A recent multicenter analysis was designed to identify variables that prolong "time to microcatheter," defined as the time interval from computed tomographic scan to microcatheter placement in the cerebral circulation. ${ }^{51}$ Ninety-one consecutive acute ischemic stroke patients from 3 academic stroke centers were studied and the mean "time to microcatheter" was $174 \pm 60$ minutes. It was significantly longer in nonlevel I trauma centers and in patients with NIHSS of 10 to 19, highlighting wide variability of "time to microcatheter" among institutions and the need for standardized time goals.

\section{CONCLUSION}

Newer endovascular technologies have greatly expanded the treatment arsenal of stroke clinicians with catheterbased drug administration, mechanical embolectomy, and angioplasty with stent placement. A multitude of articles, case series, postmarket registries, and incomplete studies all point to the continuing need for large randomized controlled studies to assess the clinical effectiveness of interventional therapy. Two such current NINDS-sponsored trials are the IMS-III (mentioned above) and Randomized MR and Recanalization of Stroke Clots by Embolectomy (MR Rescue) designed to test the effectiveness of embolectomy compared with standard medical management in 120 subjects at 30 centers who are either ineligible for IV-rtPA or who are able to have endovascular therapy initiated within 8 hours from stroke onset. ${ }^{8}$ These ongoing and many of the upcoming studies will hopefully provide level $1 \mathrm{~A}$ data for the overall benefit of interventional care in acute ischemic stroke.

\section{REFERENCES}

1. Lloyd-Jones D, Adams RJ, Brown TM, et al. American Heart Association Statistics Committee and Stroke Statistics Subcommittee. Heart disease and stroke statistics-2010 update: a report from the American Heart Association. Circulation 2010;121(7):e46-e215

2. del Zoppo GJ, Ferbert A, Otis S, et al. Local intra-arterial fibrinolytic therapy in acute carotid territory stroke. A pilot study. Stroke 1988;19(3):307-313

3. Hacke W, Zeumer H, Ferbert A, Brückmann H, del Zoppo GJ. Intra-arterial thrombolytic therapy improves outcome in patients with acute vertebrobasilar occlusive disease. Stroke 1988;19(10):1216-1222

4. Mori E, Tabuchi M, Yoshida T, Yamadori A. Intracarotid urokinase with thromboembolic occlusion of the middle cerebral artery. Stroke 1988;19(7):802-812

5. Theron J, Courtheoux P, Casasco A, et al. Local intraarterial fibrinolysis in the carotid territory. AJNR Am J Neuroradiol 1989;10(4):753-765
6. Zeumer H, Freitag HJ, Grzyska U, Neunzig HP. Local intraarterial fibrinolysis in acute vertebrobasilar occlusion. Technical developments and recent results. Neuroradiology 1989;31(4):336-340

7. Tissue plasminogen activator for acute ischemic stroke. The National Institute of Neurological Disorders and Stroke rt-PA Stroke Study Group. N Engl J Med 1995;333(24): 1581-1587

8. Broderick JP. Endovascular therapy for acute ischemic stroke. Stroke 2009;40(3, Suppl):S103-S106

9. Hacke W, Kaste M, Bluhmki E, et al; ECASS Investigators. Thrombolysis with alteplase 3 to 4.5 hours after acute ischemic stroke. N Engl J Med 2008;359(13):1317-1329

10. Bambauer KZ, Johnston SC, Bambauer DE, Zivin JA. Reasons why few patients with acute stroke receive tissue plasminogen activator. Arch Neurol 2006;63(5): 661-664

11. Barber PA, Zhang J, Demchuk AM, Hill MD, Buchan AM. Why are stroke patients excluded from TPA therapy? An analysis of patient eligibility. Neurology 2001;56(8):10151020

12. Rha JH, Saver JL. The impact of recanalization on ischemic stroke outcome: a meta-analysis. Stroke 2007;38(3):967-973

13. Nogueira RG, Schwamm LH, Hirsch JA. Endovascular approaches to acute stroke, part 1: drugs, devices, and data. AJNR Am J Neuroradiol 2009;30(4):649-661

14. Qureshi AI, Siddiqui AM, Suri MF, et al. Aggressive mechanical clot disruption and low-dose intra-arterial thirdgeneration thrombolytic agent for ischemic stroke: a prospective study. Neurosurgery 2002;51(5):1319-1327, discussion 1327-1329

15. Furlan AJ, Higashida RT. Intra-arterial thrombolysis in acute ischemic stroke. In: Mohr JP, Choi DW, Grotta JC, Weir B, Wolf PC, eds. 4 th ed. Stroke: Pathophysiology, Diagnosis, and Management. Philadelphia: Churchill Livingstone; 2004:943-953

16. von Kummer R, Holle R, Rosin L, Forsting M, Hacke W. Does arterial recanalization improve outcome in carotid territory stroke? Stroke 1995;26(4):581-587

17. del Zoppo GJ, Higashida RT, Furlan AJ, Pessin MS, Rowley HA, Gent M. PROACT: a phase II randomized trial of recombinant pro-urokinase by direct arterial delivery in acute middle cerebral artery stroke. PROACT Investigators. Prolyse in Acute Cerebral Thromboembolism. Stroke 1998; 29(1):4-11

18. Furlan A, Higashida R, Wechsler L, et al. Intra-arterial prourokinase for acute ischemic stroke. The PROACT II study: a randomized controlled trial. Prolyse in Acute Cerebral Thromboembolism. JAMA 1999;282(21): 2003-2011

19. Ernst R, Pancioli A, Tomsick T, et al. Combined intravenous and intra-arterial recombinant tissue plasminogen activator in acute ischemic stroke. Stroke 2000;31(11):2552-2557

20. Lewandowski CA, Frankel M, Tomsick TA, et al. Combined intravenous and intra-arterial r-TPA versus intra-arterial therapy of acute ischemic stroke: Emergency Management of Stroke (EMS) Bridging Trial. Stroke 1999;30(12):25982605

21. Suarez JI, Zaidat OO, Sunshine JL, Tarr R, Selman WR, Landis DM. Endovascular administration after intravenous infusion of thrombolytic agents for the treatment of patients with acute ischemic strokes. Neurosurgery 2002;50(2): 251-259, discussion 259-260 
22. Wolfe T, Suarez JI, Tarr RW, et al. Comparison of combined venous and arterial thrombolysis with primary arterial therapy using recombinant tissue plasminogen activator in acute ischemic stroke. J Stroke Cerebrovasc Dis 2008;17(3):121-128

23. Burns TC, Rodriguez GJ, Patel S, et al. Endovascular interventions following intravenous thrombolysis may improve survival and recovery in patients with acute ischemic stroke: a case-control study. AJNR Am J Neuroradiol 2008;29(10):1918-1924

24. Hill MD, Barber PA, Demchuk AM, et al. Acute intravenous-intra-arterial revascularization therapy for severe ischemic stroke. Stroke 2002;33(1):279-282

25. Shaltoni HM, Albright KC, Gonzales NR, et al. Is intraarterial thrombolysis safe after full-dose intravenous recombinant tissue plasminogen activator for acute ischemic stroke? Stroke 2007;38(1):80-84

26. Georgiadis AL, Memon MZ, Shah QA, et al. Comparison of partial $(.6 \mathrm{mg} / \mathrm{kg})$ versus full-dose $(.9 \mathrm{mg} / \mathrm{kg})$ intravenous recombinant tissue plasminogen activator Followed by endovascular treatment for acute ischemic stroke: A metaanalysis. J Neuroimaging 2009; November 10 [Epub ahead of print]

27. Keris V, Rudnicka S, Vorona V, Enina G, Tilgale B, Fricbergs J. Combined intraarterial/intravenous thrombolysis for acute ischemic stroke. AJNR Am J Neuroradiol 2001; 22(2):352-358

28. IMS Study Investigators. Combined intravenous and intra-arterial recanalization for acute ischemic stroke: the Interventional Management of Stroke Study. Stroke 2004; 35(4):904-911

29. IMS II Trial Investigators. The Interventional Management of Stroke (IMS) II Study. Stroke 2007;38(7):2127-2135

30. Tomsick T, Broderick J, Carrozella J, et al; Interventional Management of Stroke II Investigators. Revascularization results in the Interventional Management of Stroke II trial. AJNR Am J Neuroradiol 2008;29(3):582-587

31. Khatri P, Hill MD, Palesch YY, et al; Interventional Management of Stroke III Investigators. Methodology of the Interventional Management of Stroke III Trial. Int J Stroke 2008;3(2):130-137

32. Smith WS. Safety of mechanical thrombectomy and intravenous tissue plasminogen activator in acute ischemic stroke. Results of the multi Mechanical Embolus Removal in Cerebral Ischemia (MERCI) trial, part I. AJNR Am J Neuroradiol 2006;27(6):1177-1182

33. Smith WS, Sung G, Starkman S, et al; MERCI Trial Investigators. Safety and efficacy of mechanical embolectomy in acute ischemic stroke: results of the MERCI trial. Stroke 2005;36(7):1432-1438

34. Smith WS, Sung G, Saver J, et al; Multi MERCI Investigators. Mechanical thrombectomy for acute ischemic stroke: final results of the Multi MERCI trial. Stroke 2008; 39(4):1205-1212

35. Josephson SA, Saver JL, Smith WS; Merci and Multi Merci Investigators. Comparison of mechanical embolectomy and intraarterial thrombolysis in acute ischemic stroke within the MCA: MERCI and Multi MERCI compared to PROACT II. Neurocrit Care 2009;10(1):43-49

36. Bose A, Henkes H, Alfke K, et al; Penumbra Phase 1 Stroke Trial Investigators. The Penumbra System: a mechanical device for the treatment of acute stroke due to thromboembolism. AJNR Am J Neuroradiol 2008;29(7):1409-1413
37. Penumbra Pivotal Stroke Trial Investigators. The penumbra pivotal stroke trial: safety and effectiveness of a new generation of mechanical devices for clot removal in intracranial large vessel occlusive disease. Stroke 2009;40(8):27612768

38. Gounis MJ, DeLeo MJ III, Wakhloo AK. Advances in interventional neuroradiology. Stroke 2010;41(2):e81-e87

39. Struffert T, Köhrmann M, Engelhorn T, et al. Penumbra Stroke System as an "add-on" for the treatment of large vessel occlusive disease following thrombolysis: first results. Eur Radiol 2009;19(9):2286-2293

40. Abou-Chebl A, Bajzer CT, Krieger DW, Furlan AJ, Yadav JS. Multimodal therapy for the treatment of severe ischemic stroke combining GPIIb/IIIa antagonists and angioplasty after failure of thrombolysis. Stroke 2005;36(10):22862288

41. Nakano S, Iseda T, Yoneyama T, Kawano H, Wakisaka S. Direct percutaneous transluminal angioplasty for acute middle cerebral artery trunk occlusion: an alternative option to intra-arterial thrombolysis. Stroke 2002;33(12):2872-2876

42. Ueda T, Sakaki S, Nochide I, Kumon Y, Kohno K, Ohta S. Angioplasty after intra-arterial thrombolysis for acute occlusion of intracranial arteries. Stroke 1998;29(12):25682574

43. Qureshi AI, Siddiqui AM, Kim SH, et al. Reocclusion of recanalized arteries during intra-arterial thrombolysis for acute ischemic stroke. AJNR Am J Neuroradiol 2004;25(2): 322-328

44. Nogueira RG, Schwamm LH, Buonanno FS, et al. Lowpressure balloon angioplasty with adjuvant pharmacological therapy in patients with acute ischemic stroke caused by intracranial arterial occlusions. Neuroradiology 2008;50(4): 331-340

45. Levy EI, Siddiqui AH, Crumlish A, et al. First Food and Drug Administration-approved prospective trial of primary intracranial stenting for acute stroke: SARIS (stent-assisted recanalization in acute ischemic stroke). Stroke 2009;40(11): 3552-3556

46. Jahan R. Solitaire flow-restoration device for treatment of acute ischemic stroke: Safety and recanalization efficacy study in a swine vessel occlusion model. AJNR Am J Neuroradiol 2010;(Jul):15 [Epub ahead of print]

47. TIMI Study Group. The Thrombolysis in Myocardial Infarction (TIMI) trial. Phase I findings. N Engl J Med 1985;312(14):932-936

48. Qureshi AI. New grading system for angiographic evaluation of arterial occlusions and recanalization response to intraarterial thrombolysis in acute ischemic stroke. Neurosurgery 2002;50(6):1405-1414, discussion 1414-1415

49. Mohammad Y, Xavier AR, Christoforidis G, Bourekas E, Slivka A. Qureshi grading scheme for angiographic occlusions strongly correlates with the initial severity and inhospital outcome of acute ischemic stroke. J Neuroimaging 2004;14(3):235-241

50. Hussein HM, Georgiadis AL, Vazquez G, et al. Occurrence and predictors of futile recanalization following endovascular treatment among patients with acute ischemic stroke: a multicenter study. AJNR Am J Neuroradiol 2010;31(3):454458

51. Miley JT, Memon MZ, Hussein HM, et al. A multicenter analysis of "time to microcatheter" for endovascular therapy in acute ischemic stroke. J Neuroimaging 2009; October 7 [Epub ahead of print] 